\title{
Association between Obesity and Adult Attention-Deficit/Hyperactivity Disorder in a German Community-Based Sample
}

\author{
Martina de Zwaan ${ }^{a} \quad$ Barbara Gruß ${ }^{a} \quad$ Astrid Müller ${ }^{a} \quad$ Alexandra Philipsen $^{b}$ Holmer Graap \\ Alexandra Martin ${ }^{\mathrm{a}}$ Heide Glaesmer ${ }^{\mathrm{c}}$ Anja Hilbert ${ }^{\mathrm{d}}$ \\ ${ }^{a}$ Department of Psychosomatic Medicine and Psychotherapy, University of Erlangen-Nuremberg, \\ ${ }^{\mathrm{b}}$ Department of Psychiatry and Psychotherapy, University of Freiburg, \\ ${ }^{c}$ Department of Medical Psychology and Medical Sociology, University of Leipzig, Germany \\ ${ }^{\mathrm{d}}$ Department of Clinical Psychology, University of Fribourg, Switzerland
}

\begin{abstract}
Keywords
Adult attention-deficit/hyperactivity disorder .

ADHD · Obesity · Epidemiology · Binge eating ·

Purging · Depression · Anxiety
\end{abstract}

\section{Summary}

Objective: The goal of the present study was to examine the association between attention-deficit/hyperactivity disorder (ADHD) and obesity in a representative community based sample of the German population. Method: Participants were 1,633 German residents $153.6 \%$ female) aged 18-64 years. A retrospective assessment of childhood ADHD and a self-report assessment of adult ADHD were administered for diagnosis of adult ADHD. In addition, binge eating and purging behaviors as well as depression and anxiety were assessed using selfrating instruments. Results: The estimated prevalence of ADHD in obese participants was $9.7 \%$ compared to $3.8 \%$ in overweight and $4.3 \%$ in under-/normal-weight participants. The prevalence of obesity was $22.1 \%$ among adults with ADHD and $10.2 \%$ among persons without ADHD. Adult ADHD was significantly associated with a greater likelihood of being obese but not overweight even after adjusting for sociodemographic characteristics. Results were similar when adjusting for depression and anxiety symptoms and for purging behaviors. Odds ratios decreased after adjusting for binge eating; however, the results were still significant which shows that the relationship between obesity and ADHD in adulthood is not fully explained by binge eating. Conclusion: Overall, the results indicate that adult ADHD is associated with obesity in a community-based sample of the adult German population.

\section{Introduction}

Longitudinal evidence suggests that childhood attention-deficit/hyperactivity disorder (ADHD) persists into adulthood in $60-70 \%$ of cases and thus can be conceived as a life-span disorder with childhood-onset $[1,2]$. In representative community-based samples of individuals aged $18-44$ years the prevalence rate of adult ADHD has been estimated to be 1.2-7.3\% in 10 European and non-European countries [3, 4]. Whereas in childhood affected boys outnumber girls, in adults the sex ratio tends to be more equal [5]. The diagnosis in adulthood requires a positive childhood diagnosis (DSM-IV) [6], at least assessed retrospectively. Adult ADHD should be evident across different situations and lead to substantial distress as well as impairment in at least two areas of living. No other disorders should explain the symptoms better; however, a high co-morbidity with other psychiatric disorders has been documented. In fact ADHD alone, without other co-morbid disorder, occurs in a minority of cases $[5,7,8]$.

Growing evidence shows that there is a strong link between the proneness to obesity and ADHD in children [9-15]. A large US study found that untreated youth with ADHD had about 1.5 times the odds of being overweight [16]. Surprisingly, being 'hyperactive' or 'physically restless' in the sense of the DSM-IV diagnosis of ADHD does not prevent the development or persistence of overweight and obesity in children [9].

\section{KARGER \\ Fax +497614520714 \\ Information@Karger.de}

www.karger.com
(C) 2011 S. Karger GmbH, Freiburg

$1662-4025 / 11 / 0043-0204 \$ 38.00 / 0$

Accessible online at:

www.karger.com/ofa
Prof. Dr. Martina de Zwaan

Department of Psychosomatic Medicine and Psychotherapy

University Hospital of Erlangen

Schwabachanlage 6, 91054, Erlangen, Germany

Tel. +49 9131 853-5928, Fax -4153

martina.dezwaan@uk-erlangen.de 
The association between ADHD and obesity in adults has been explored in three studies conducted with obese weight loss samples [17-19]. Altfas [19] found a frequency of current adult ADHD of $27.4 \%$ in a sample of 215 obese weight loss participants. The author also reported that the prevalence increased with the degree of obesity $(42.6 \%$ in extremely obese patients with a BMI $>40 \mathrm{~kg} / \mathrm{m}^{2}$ ) and that patients with ADHD were significantly less successful at losing weight compared to non-ADHD patients. Fleming et al. [17] reported a prevalence of current adult ADHD of $26.6 \%$ in 75 female weight loss participants. In a further study of 190 severely obese patients with a mean BMI of $40.4 \mathrm{~kg} / \mathrm{m}^{2}$ the authors identified between 33.7 and $38.2 \%$ of the patients as having ADHD depending of the measures employed. Finally, Levy et al. [18] reported that severely obese adults lost significantly more weight when treated with pharmacotherapy for ADHD $(-12.4 \%)$ compared to controls who gained $2.8 \%$ of their initial weight after a mean observation period of 1 year and 3 months. According to the authors, the appetite suppression effect of the stimulant medication used (amphetamine, methylphenidate) was transient and did not explain the long-term reduction in calorie intake. They hypothesized that the medication improved behavioral regulation and self-directedness and thus facilitated intentional weight loss. Also binge eating decreased substantially. The authors suggested considering ADHD as a primary cause of weight loss failure in adults with refractory obesity.

The above mentioned studies were conducted in clinical settings, and, therefore, their results may not reflect the prevalence of ADHD in obese persons in the general population. Recently, Pagoto et al. [20] reported a significant positive association between adult ADHD and obesity as well as overweight in a population based sample of US adults aged 18-44 years $(n=6,735)$. They found a prevalence rate of obesity and overweight of $29.4 \%$ and $33.9 \%$, respectively, among adults with ADHD; among persons with no history of ADHD the respective values were $21.6 \%$ and $28.8 \%$. Binge eating disorder but not depression partially mediated the association between ADHD and overweight and obesity.

Besides the association between obesity and ADHD in clinical and community samples there is considerable evidence for an association between ADHD and pathological eating behavior [21-24]. Binge eating behavior and purging behavior such as those seen in binge eating disorder and bulimia nervosa frequently occur in patients with ADHD. Palazzo Nazar et al. [21] concluded that adult women with ADHD are at higher risk for developing eating disorders, especially bulimia nervosa. In their review of the literature they found prevalence rates of bulimia nervosa in patients with ADHD ranging from 1 to $12 \%$. Longitudinal studies revealed that youth with ADHD develop higher rates of body dissatisfaction and bingeing/purging behaviors in adolescence compared to youth without ADHD [22]. Impulsivity may be a causal mechanism for the link between binge eating and purg- ing behaviors and ADHD. This supports the assumption that pathological eating behavior associated with ADHD might be a relevant mediator for the association between ADHD and obesity [20].

In summary the data to date demonstrate that adult ADHD is highly prevalent in samples of obese weight loss participants, but may also be in obese population-based samples. The aim of the study was i) to investigate the association between adult ADHD and overweight and obesity in a large representative German community-based sample and ii) to investigate possible eating-related (binge eating, purging) and general (depression, anxiety) psychopathological mediators of this association.

\section{Material and Methods}

\section{Study Sample}

A representative sample of the German general population was selected with the assistance of a demographic consulting company (USUMA, Berlin, Germany). The sample was selected to be representative in terms of age, sex and education. The area of Germany was separated into 258 sample areas representing the different regions of the country. Households of the respective area and members of the household fulfilling the inclusion criteria (age at or above 14, able to read and understand the German language) were selected randomly. The household respondent was selected using a random process (kish selection grid). A first attempt was made for 4,091 addresses, of which 4,069 were valid. If not at home, a maximum of three attempts was made to contact the selected person. All subjects were visited by a study assistant who informed them about the investigation, obtained written informed consent and presented them with the self-rating questionnaires (see below). The assistant waited until participants answered all questionnaires and offered help if persons did not understand the meaning of questions. A total of 2,520 people aged between 14 and 93 years agreed to participate and completed the selfrating questionnaires (participation rate: $61.9 \%$ of valid addresses) between November 27 and December 16, 2009. All respondents whose age was below $18(\mathrm{n}=100)$ and above 64 years $(\mathrm{n}=695)$ were excluded for the present study. There is concern about the accuracy of retrospective recall of childhood symptoms and about the validity of the self-rating instruments for childhood and current ADHD symptoms in older adults. In addition, participants who did not fully complete the central diagnostic instruments (WURS-k and ADHD-SR) and those who did not provide weight data were excluded from further analyses. This provided a final sample of 1,633 individuals for analysis.

The population-based survey met the ethical guidelines of the international Code of Marketing and Social Research Practice by the International Chamber of Commerce and the European Society for Opinion and Marketing Research.

\section{Assessment}

\section{Assessment of ADHD Symptomatology}

Childhood and adult ADHD were assessed using standard self-report screening instruments. Participants rated their ADHD symptoms in childhood retrospectively, using the German version of the short version of the Wender Utah Rating Scale (WURS-k) [25-27], which consists of 25 items on a five-point Likert scale (0-4, 'not at all' to 'severe'). The internal consistency in our sample was 0.92 (Cronbach's $\alpha$ ). As suggested by the authors we used a cut-off score of $\geq 30$ to indicate the presence of a diag- 
nosis of ADHD in childhood (age 8-10 years). This cut-off has a sensitivity of $85 \%$ and a specificity of $76 \%$ [26].

Participants rated adult ADHD symptoms with the ADHD self rating scale (ADHD-SR) [27, 28], which includes the 18 DSM-IV items of inattention, hyperactivity and impulsivity on a four-point Likert scale (0-3, 'not at all' to 'severe'). The internal consistency in our sample was 0.92 (Cronbach's $\alpha$ ). When comparing self-rating with expert rating good agreement was found as measured by intraclass coefficients for individual symptoms (0.41-0.92) and for the total score (0.87) [28]. The recommended cut-off of $\geq 15$ was used to indicate that participants met criteria for adult ADHD. This cut-off has a sensitivity of $77 \%$ and a specificity of $75 \%$ for adult ADHD [28]. Only participants who fulfilled both the WURS-k criteria and the ADHD-SR criteria were diagnosed as probable cases of adult ADHD.

\section{Height and Body Weight}

Based on the participants' self-reported height and weight, the BMI $\left(\mathrm{kg} / \mathrm{m}^{2}\right)$ was calculated. For the purpose of the present study BMI was recorded into a three category variable: under/normal-weight (BMI $\leq 25$ $\mathrm{kg} / \mathrm{m}^{2}$ ), overweight (BMI $25.1-29.9 \mathrm{~kg} / \mathrm{m}^{2}$ ) and obesity $\left(\right.$ BMI $\geq 30 \mathrm{~kg} / \mathrm{m}^{2}$ ).

\section{Eating Behavior}

The Eating Disorder Examination Questionnaire (EDE-Q [29]; German version [30]) is the self-report version of the gold standard interview Eating Disorder Examination (EDE [31]; German version [32]) with good reliability and validity. EDE-Q diagnostic items were used to assess the occurrence of objective binge eating episodes (OBEs) during the past 4 weeks. OBEs are defined according to DSM-IV-TR criteria as eating an objectively large amount of food with a feeling of a loss of control.

There is evidence from population studies that the frequency of OBEs is higher when assessed with interview which might result in an underestimation of the prevalence of eating disorders and their subsyndromal variants by the self-report version EDE-Q. However, the occurrence of one or more OBEs assessed with the EDE-Q discriminated well between cases and non-cases of eating disorders [33] and thus this dichotomous variable ( $<$ or $\geq 1 \mathrm{OBE}$ during the past 4 weeks) was used in the analyses. The EDE-Q also assesses the frequency of different forms of purging behavior, namely self-induced vomiting as well as laxative and diuretic misuse. The number of participants who reported one or more purging episode during the last 4 weeks was calculated. There is evidence that individuals are more willing to disclose potentially embarrassing behaviors such as purging in a questionnaire than in a faceto-face interview [34].

\section{Depression and Anxiety}

The 4-item Patient Health Questionnaire (PHQ-4) is an ultra-brief selfreport questionnaire for use as an overall screening tool for depression and anxiety [35] (German version [36]). It consists of a 2-item depression scale (PHQ-2 [37, 38]) and a 2-item anxiety scale (GAD-2 [36, 39]). Response options range from 0 ('not at all') to 3 ('nearly every day') for each of the four questions. The symptoms are assessed for the last 2 weeks. Since the subscales PHQ-2 and GAD-2 are highly intercorrelated $(r=0.61)$ the authors suggested considering the PHQ-4 total scale as an overall screening tool for depression and anxiety. A cut-off of $\geq 6$ has been suggested for the presence of a depressive or an anxiety disorder, representing a percentile of $95.7 \%$ in a large population based sample $(\mathrm{N}=5,030)$ [36]. For the analyses a dichotomous variable with a cut-off of 6 and above on the PHQ-4 was used.

\section{Statistics}

All statistical analyses were conducted using the statistical package PASW 18.0.0 for Windows. Associations between weight categories and adult ADHD with sociodemographic characteristics, presence of OBEs and purging behaviors, and screenings for depression and anxiety were determined using chi square tests. Multinomial regression analyses were conducted with the three BMI categories as dependent variable and the presence/absence of adult ADHD as the main independent variable. In a next step we followed the procedure presented by Baron and Kenny [40] for examining the possible mediating effect of variables that were significantly correlated with the dependent variable (BMI categories) as well as with the main independent variable (ADHD). One multinomial regression analysis was carried out controlling for the occurrence of OBEs, one controlling for the occurrence of purging behaviors and one controlling for depression and anxiety. All regression analyses were conducted controlling for sex, age, educational level, marital status, employment status and urbanicity (urban/rural residency). An $\alpha$-level of 0.05 was adopted for all tests. First, unweighted data were used for the multinomial regression analyses. In addition, analyses were repeated after a weighing procedure for age, sex and state of residency according to the distribution of these sociodemographic factors in the German adult population as given by the Federal Statistics Office.

\section{Results}

\section{Study Sample}

A description of the study sample $(n=1,633)$ is given in table 1. The mean age of the sample was 43.2 years (SD 12.7 years), with $53.6 \%$ being female. $53.9 \%$ were married, $8.6 \%$ were unemployed, and $15.8 \%$ had finished high school or attained education beyond high school. Screening for current depression and anxiety with the PHQ-4 revealed positive results in $5.6 \%$ of the sample; $3.9 \%$ of the sample reported current OBEs and $2.8 \%$ current purging behaviors (self-induced vomiting, laxative or diuretic misuse for weight and shape reasons).

\section{ADHD Categories and Correlates}

A previous report based on the same sample showed that the prevalence of adult ADHD was $4.7 \%$ in our sample of German adults aged 18-64 years [41]. Participants with adult ADHD were more often unemployed, had a lower educational level and were more often living in a rural area. Adult ADHD was almost equally distributed between men and women, and no significant differences were found for age. Adult ADHD was significantly and positively associated with the occurrence of current OBEs and purging behaviors as well as positive screening results for current depression and anxiety (table 1).

\section{BMI Categories and Correlates}

Half $(55 \%)$ of the sample reported a BMI $\leq 25 \mathrm{~kg} / \mathrm{m}^{2}$ indicating underweight or normal-weight, $34.3 \%$ reported a BMI between 25.0 and $29.9 \mathrm{~kg} / \mathrm{m}^{2}$ indicating overweight, and $10.7 \%$ a BMI of $\geq 30 \mathrm{~kg} / \mathrm{m}^{2}$ indicative of obesity.

Obesity was significantly associated with female gender, higher age and lower educational level. No significant differences were found for urbanicity and employment status. Finally, OBEs, purging behaviors, and positive screening results for depression and anxiety were all significantly more prevalent in obese individuals (table 2). 
Table 1. Distribution of sociodemographic characteristics, BMI, pathological eating behavior, and depression/anxiety by ADHD categories (\%)

\begin{tabular}{|c|c|c|c|c|}
\hline Variables & $\begin{array}{l}\text { Total sample } \\
(\mathrm{n}=1,633)\end{array}$ & $\begin{array}{l}\text { No ADHD } \\
(\mathrm{n}=1,556)\end{array}$ & $\begin{array}{l}\text { Adult ADHD } \\
(\mathrm{n}=77)\end{array}$ & Statistics $^{\mathrm{a}}$ \\
\hline \multicolumn{5}{|l|}{ Gender } \\
\hline Female & 53.6 & 53.6 & 54.5 & $\chi^{2}=0.026, \mathrm{df}=1, \mathrm{~ns}$ \\
\hline \multicolumn{5}{|l|}{ Age, years } \\
\hline $18-24$ & 9.9 & 9.4 & 19.5 & \multirow{5}{*}{$\chi^{2}=8.918, \mathrm{df}=4, \mathrm{~ns}$} \\
\hline $25-34$ & 17.3 & 17.4 & 14.3 & \\
\hline $35-44$ & 23.9 & 23.9 & 23.4 & \\
\hline $45-54$ & 25.2 & 25.3 & 24.7 & \\
\hline $55-64$ & 23.7 & 24.0 & 18.2 & \\
\hline \multicolumn{5}{|l|}{ Educational level } \\
\hline$\geq 12$ years & 12.8 & 16.5 & 2.6 & $\chi^{2}=10.587, \mathrm{df}=1, \mathrm{p}=0.001$ \\
\hline \multicolumn{5}{|l|}{ Marital status } \\
\hline Married & 53.9 & 54.8 & 36.4 & \multirow{4}{*}{$\chi^{2}=10.408, \mathrm{df}=3, \mathrm{p}=0.01$} \\
\hline Never married & 27.7 & 27.1 & 39.0 & \\
\hline Divorced & 14.6 & 14.3 & 20.8 & \\
\hline Widowed & 3.8 & 3.8 & 3.9 & \\
\hline \multicolumn{5}{|l|}{ Employment status } \\
\hline Unemployed & 8.6 & 7.8 & 24.7 & $\chi^{2}=26.358, \mathrm{df}=1, \mathrm{p}<0.001$ \\
\hline \multicolumn{5}{|l|}{ Urbanicity } \\
\hline Urban & 88.4 & 89.3 & 70.1 & \multirow{2}{*}{$\chi^{2}=26.433, \mathrm{df}=1, \mathrm{p}<0.001$} \\
\hline Rural & 11.6 & 10.7 & 29.9 & \\
\hline \multicolumn{5}{|l|}{ BMI categories } \\
\hline Under-/normal-weight & 55.0 & 55.2 & 50.6 & \multirow{3}{*}{$\chi^{2}=11.172, \mathrm{df}=2, p<0.01$} \\
\hline Overweight & 34.3 & 34.6 & 27.3 & \\
\hline Obesity & 10.7 & 10.2 & 22.1 & \\
\hline \multicolumn{5}{|c|}{ Occurrence of objective binge eating episodes (EDE-Q) } \\
\hline Yes $(n=64)$ & 3.9 & 3.5 & 13.0 & $\chi^{2}=17.646, \mathrm{df}=1, \mathrm{p}<0.001$ \\
\hline \multicolumn{5}{|c|}{ Occurrence of purging behavior (EDE-Q) } \\
\hline Yes $(n=46)$ & 2.8 & 2.6 & 7.8 & $\chi^{2}=7.307, \mathrm{df}=1, \mathrm{p}<0.01$ \\
\hline \multicolumn{5}{|l|}{ Depression/Anxiety (PHQ-4) } \\
\hline Cut-off $\geq 6(n=92)$ & 5.6 & 4.6 & 27.3 & $\chi^{2}=71.174, \mathrm{df}=1, \mathrm{p}<0.001$ \\
\hline
\end{tabular}

PHQ-4 = Patient Health Questionnaire-4; EDE-Q = Eating Disorder Examination-Questionnaire; ns = not significant.

${ }^{\mathrm{a}}$ Chi-square tests; difference between participants with and without adult ADHD.

\section{Is ADHD Predictive of Obesity?}

Obesity was significantly and positively associated with adult ADHD. The estimated prevalence of ADHD in obese participants was $9.7 \%(\mathrm{n}=17)$ compared to $3.8 \%(\mathrm{n}=21)$ in overweight and $4.3 \%(\mathrm{n}=39)$ in under-/normal-weight participants. Obesity was more prevalent among persons with adult ADHD $(22.1 \% ; \mathrm{n}=17)$ than among those without adult $\operatorname{ADHD}(10.2 \% ; \mathrm{n}=158)$.

In the crude multinomial logistic regression, adult ADHD was associated with statistically significant increases in the odds of being obese (obese odds ratio $(\mathrm{OR})=2.37$; $95 \% \mathrm{CI}=$ 1.31-4.29) but not of being overweight. The results were unchanged in the analysis, which adjusted for demographics (age, sex, educational level, employment status, marital status, urbanicity) (obese $\mathrm{OR}=2.42 ; 95 \% \mathrm{CI}=1.26-4.65$ ) (table 3 ). Depression and anxiety as well as purging behaviors did not explain the association between adult ADHD and obesity; the OR of the association between adult ADHD and obesity did not decrease compared to the unadjusted models. After adjusting for OBEs the OR decreased from 2.4 to 2.0 but the association between obesity and adult ADHD remained statistically significant (Wald $\chi 2=4.83, p=0.028)$ (table 4$)$.

The analyses were repeated with the weighted sample. The results of the multinomial regression analyses did not change compared to the results with the unweighted sample. 
Table 2. Distribution of sociodemographic characteristics, ADHD, pathological eating behavior, and depression/anxiety by BMI categories (\%)

\begin{tabular}{|c|c|c|c|c|}
\hline Variables & $\begin{array}{l}\text { Under-/normal- } \\
\text { weight } \\
(\mathrm{n}=898)\end{array}$ & $\begin{array}{l}\text { Overweight } \\
(\mathrm{n}=560)\end{array}$ & $\begin{array}{l}\text { Obesity } \\
(\mathrm{n}=175)\end{array}$ & Statistics \\
\hline \multicolumn{5}{|l|}{ Gender } \\
\hline Female & $60.2^{\mathrm{a}}$ & $40.7^{\mathrm{b}}$ & $61.1^{\mathrm{a}}$ & $\chi^{2}=57.340, \mathrm{df}=2, \mathrm{p}<0.001$ \\
\hline \multicolumn{5}{|l|}{ Age, years } \\
\hline $18-24$ & $14.5^{\mathrm{a}}$ & $4.5^{\mathrm{b}}$ & $4.0^{\mathrm{b}}$ & \multirow{5}{*}{$\chi^{2}=143.249, \mathrm{df}=8, \mathrm{p}<0.001$} \\
\hline $25-34$ & 22.5 & 12.0 & 7.4 & \\
\hline $35-44$ & 25.4 & 23.0 & 18.9 & \\
\hline $45-54$ & 21.9 & 28.8 & 30.9 & \\
\hline $55-64$ & 15.7 & 31.8 & 38.9 & \\
\hline \multicolumn{5}{|l|}{ Educational level } \\
\hline$\geq 12$ years & $19.6^{\mathrm{a}}$ & $13.0^{\mathrm{b}}$ & $5.1^{\mathrm{c}}$ & $\chi^{2}=27.900, \mathrm{df}=2, \mathrm{p}<0.001$ \\
\hline \multicolumn{5}{|l|}{ Marital status } \\
\hline Married & $48.7^{\mathrm{a}}$ & $60.7^{\mathrm{b}}$ & $58.9^{\mathrm{b}}$ & \multirow{4}{*}{$\chi^{2}=51.865, \mathrm{df}=6, \mathrm{p}<0.001$} \\
\hline Never married & 33.9 & 20.9 & 17.7 & \\
\hline Divorced & 14.8 & 14.3 & 14.9 & \\
\hline Widowed & 2.7 & 4.1 & 8.6 & \\
\hline \multicolumn{5}{|l|}{ Employment status } \\
\hline Unemployed & $7.9^{\mathrm{a}}$ & $8.6^{\mathrm{ab}}$ & $12.6^{\mathrm{b}}$ & $\chi^{2}=4.044, \mathrm{df}=2, \mathrm{~ns}$ \\
\hline \multicolumn{5}{|l|}{ Urbanicity } \\
\hline Urban & 89.2 & 88.6 & 84.0 & \multirow{2}{*}{$\chi^{2}=3.884, \mathrm{df}=2, \mathrm{~ns}$} \\
\hline Rural & 10.8 & 11.4 & 16.0 & \\
\hline \multicolumn{5}{|l|}{ ADHD } \\
\hline Adult ADHD ( $\mathrm{n}=77)$ & $4.3^{\mathrm{a}}$ & $3.8^{\mathrm{a}}$ & $9.7^{\mathrm{b}}$ & $\chi^{2}=11.172, \mathrm{df}=2, \mathrm{p}<0.01$ \\
\hline \multicolumn{5}{|c|}{ Occurrence of objective binge eating episodes (EDE-Q) } \\
\hline Yes $(\mathrm{n}=64)$ & $2.2^{\mathrm{a}}$ & $5.0^{\mathrm{b}}$ & $9.1^{\mathrm{c}}$ & $\chi^{2}=21.246, \mathrm{df}=2, \mathrm{p}<0.001$ \\
\hline \multicolumn{5}{|c|}{ Occurrence of purging behavior (EDE-Q) } \\
\hline Yes $(n=46)$ & $2.2^{\mathrm{a}}$ & $2.5^{\mathrm{a}}$ & $6.9^{\mathrm{b}}$ & $\chi^{2}=11.781, \mathrm{df}=2, \mathrm{p}<0.01$ \\
\hline \multicolumn{5}{|l|}{ Depression/Anxiety (PHQ-4) } \\
\hline Cut-off $\geq 6(n=92)$ & $5.3^{\mathrm{a}}$ & $4.8^{\mathrm{a}}$ & $9.7^{\mathrm{b}}$ & $\chi^{2}=6.317, \mathrm{df}=2, \mathrm{p}<0.05$ \\
\hline
\end{tabular}

PHQ-4 = Patient Health Questionnaire-4; EDE-Q = Eating Disorder Examination-Questionnaire; ns = not significant.

Values with different superscripts are significantly different (pair-wise contrasts with chi-square tests among two groups).

\section{Discussion}

This is the first community-based study to examine the association between ADHD and obesity in adults conducted in a representative European sample. Our results demonstrate that having adult ADHD significantly increased the odds of being obese. This association held true even after controlling for potential confounding factors such as socioeconomic status, depression and anxiety symptoms. After adjusting for OBEs, the OR decreased somewhat but the association between obesity and adult ADHD remained significant, suggesting that the association is only partly explained by binge eating behavior. Purging behaviors such as self-induced vomiting as well as laxative and diuretic misuse did not explain the association between adult ADHD and obesity. The results did not change regardless if weighted or unweighted data were used. The cross-sectional nature of our data precludes causal conclusions; however, temporal precedence of ADHD over obesity is likely [3].

Current OBEs were reported by $9.1 \%$ of participants with obesity and by $13 \%$ of participants with adult ADHD. Most former studies found a strong association between binge eating disorder and adult ADHD, suggesting that dysregulated eating could explain the link between ADHD and obesity [20, 42, 43]. It has been hypothesized that both the inattentive and impulsive component associated with ADHD may contribute to disordered eating patterns including binge eating. In our obesigenic environment this might increase the risk for the development of obesity [23, 24]. In addition, a dysregulation of executive functions, which are largely regulated by the pre- 
Table 3. Multinomial logistic regression models of the association between ADHD and overweight and obesity

\begin{tabular}{lll}
\hline $\mathrm{N}=1,633$ & $\begin{array}{l}\text { Overweight (vs. normal) } \\
\text { odds ratio (95\% CI) }\end{array}$ & $\begin{array}{l}\text { Obese (vs. normal) } \\
\text { odds ratio (95\% CI) }\end{array}$ \\
\hline $\begin{array}{l}\text { Unadjusted model } \\
\text { ADHD }\end{array}$ & & \\
$\quad$ No & & 1.0 \\
$\quad$ Adult & 1.0 & $2.37(1.31-4.29)^{* *}$ \\
\hline $\begin{array}{l}\text { Adjusted model } \\
\text { ADHD }\end{array}$ & $0.86(0.49-1.47)$ & \\
No & & 1.0 \\
Adult & 1.0 & $2.42(1.26-4.65)^{* *}$ \\
\hline
\end{tabular}

*Adjusted for demographics (age, gender, educational level, employment status, marital status, rural/urban residency).

$* * \mathrm{p}<0.01$.

frontal cortex and are responsible for reasoning, planning, inhibition and decision making might lead to low effortful control of food intake [24, 44]. In other words, individuals with high impulsivity, inattentiveness and poor self-regulation may turn to binge eating and such eating pattern may result in a higher BMI among individuals with ADHD. In line with this hypothesis, Pagoto et al. [20] reported in their epidemiological study that binge eating disorder mediated the observed association between ADHD and obesity. We could partly confirm this association. OBEs were strongly related to obesity as well as to adult ADHD, and controlling for OBEs weakened the association between adult ADHD and obesity. However, the association between ADHD and obesity remained significant. In line with our results, Davis et al. [45] reported that obese subjects with and without binge eating disorder did not differ in symptoms of inattention and hyperactivity/impulsivity, neither in childhood nor in adulthood. Based on these results, it might be hypothesized that ADHD symptoms are associated with many forms of pathological (over)eating behavior such as grazing, and not only with binge eating.

An alternative explanation for the association between obesity and ADHD might be that food intake may be used to increase dopaminergic transmission and reduce the hypodopaminergic state that has been associated with ADHD [46, 47]. Thus it has been suggested that food might serve as a form of self-medication in individuals with ADHD [24]. Finally, it cannot be excluded that ADHD and binge eating might be caused by a common underlying neurobiological mechanism [23].

We found a close association between purging behaviors (vomiting, laxatives, diuretics) and ADHD as well as obesity in our sample. However, purging behaviors did not modify the association between ADHD and obesity. One could expect individuals with compensatory behaviors to exhibit a lower body weight; however, purging might be a consequence of body dissatisfaction due to binge eating and obesity, espe-
Table 4. Multinomial logistic regression models of the association between ADHD and overweight and obesity, adjusting for objective binge eating episodes (OBEs), purging behaviors, depression and anxiety

\begin{tabular}{|c|c|c|}
\hline $\mathrm{N}=1,633$ & $\begin{array}{l}\text { Overweight (vs. normal) } \\
\text { Odds ratio ( } 95 \% \text { CI) }\end{array}$ & $\begin{array}{l}\text { Obese (vs. normal) } \\
\text { Odds ratio }(95 \% \text { CI })\end{array}$ \\
\hline \multicolumn{3}{|c|}{$\begin{array}{l}\text { OBE adjusted } \\
\text { model }^{*}\end{array}$} \\
\hline \multicolumn{3}{|l|}{ ADHD } \\
\hline No & 1.0 & 1.0 \\
\hline Adult & $0.92(0.51-1.66)$ & $2.09(1.08-4.07)^{* * *}$ \\
\hline \multicolumn{3}{|c|}{$\begin{array}{l}\text { Purging adjusted } \\
\quad \text { model }^{*}\end{array}$} \\
\hline \multicolumn{3}{|l|}{ ADHD } \\
\hline No & 1.0 & 1.0 \\
\hline Adult & $0.99(0.55-1.78)$ & $2.25(1.16-4.35)^{* * *}$ \\
\hline \multicolumn{3}{|c|}{$\begin{array}{l}P H Q \text {-4-adjusted } \\
\quad \text { model* }\end{array}$} \\
\hline \multicolumn{3}{|l|}{ ADHD } \\
\hline No & 1.0 & 1.0 \\
\hline Adult & $1.04(0.58-1.89)$ & $2.28(1.17-4.45)^{* * *}$ \\
\hline
\end{tabular}

*Also adjusted for demographics (age, gender, educational level, employment status, marital status, rural/urban residency). $* * * \mathrm{p}<0.05$.

cially in individuals with high impulsivity. This is supported by the significant association between purging behaviors and OBEs that we found in our sample. Of those with OBEs, $20.3 \%$ reported purging behavior as opposed to only $2.1 \%$ of those without OBEs $\left(\chi^{2}=74.48, \mathrm{df}=1, \mathrm{p}<0.001\right)$. The association between purging behaviors and ADHD has never been investigated before in an adult community sample and requires further study.

There are several notable strengths of the present research including the large sample size and the representativeness of the study sample. This is the first study conducted in Europe investigating the link between ADHD and obesity in a representative, community-based sample. There are also a number of weaknesses. First, we used self-rating instruments to estimate the prevalence of ADHD and short screening instruments instead of clinical interviews to assess depression and anxiety symptoms, binge eating and purging behavior. Moreover, due to the large sample size psychiatric and somatic differential diagnoses which may cause ADHD-like symptoms such as primary sleep disorders (e.g. sleep apnoe syndrome) were not assessed [48]. Thus, results should be replicated by using semi-structured interviews and biological investigations to ensure the theoretical and clinical validity. However, the assessment methods employed in this study have been validated extensively and have been used in other clinical and community-based samples [33, 34, 36, 41, 49]. Another limitation to the field in general is that the DSM-IV [6] ADHD criteria were developed for children and may not be appropriate in adulthood $[3,50]$. In addition, there is con- 
cern about the ability of adults to recall ADHD symptoms in childhood. Mannuzza et al. [51] argue that the use of general adult population surveys to estimate the prevalence of childhood ADHD would be expected to yield substantial overestimation. However, Murphy and Schachar [52] compared subject and informant ratings of childhood and current ADHD symptoms in two adult samples and found significant correlations between subjects' and informants' ratings of $r=0.79$ and $r=0.69$, respectively.

A further limitation is that weight and height are based on self-reported data. There are inconsistent opinions as to how accurate self-report data are. Several studies have shown that self-reported previous and current weights are valid measures of actual weight $[53,54]$; however, others have demonstrated an underreporting of current body weight [55]. Overall, there seems to be a trend of underestimating weight and overestimating height [56]. Despite these limitations inherent to selfreport data on body weight and height, large-scale epidemiological studies in the USA [20] and in the EU [57] rely on selfreported weight data.

In summary, our results confirm that ADHD in the adult population is linked to obesity, OBEs, purging behaviors and depression/anxiety symptoms also in a representative German community sample. Thus we could replicate and extend results of others in a different sample using other validated measures of both ADHD and eating-related as well as general psychopathology. For clinical implications, clinicians should be aware of ADHD among obese patients even though the presence of ADHD in obese adults might appear counterintuitive. First, ADHD is associated with psychiatric co-morbidity and functional impairment that might add to the already impairing condition of obesity. In addition, the presence of ADHD in obese patients might lead to difficulties in weight loss. Especially the link between ADHD and pathological eating behavior such as binge eating and purging might interfere with the ability to intentionally reduce weight. Future treatment development might focus on whether different interventions are needed for obese patients with ADHD with regard to psychopharmacological and psychotherapeutic treatment options.

\section{Acknowledgment}

The study was supported in part by a grant from the German Federal Ministry of Education and Research (BMBF, 01GI0835) within the German Competence Network of Obesity. The BMBF had no further role in study design; in the collection, analysis and interpretation of data; in the writing of the report; and in the decision to submit the paper for publication.

\section{Disclosure Statement}

The authors declare no conflict of interest.

\section{References}

1 Kessler RC, Adler LA, Barkley R, Biederman J, Conners CK, Faraone SV, Greenhill LL, Jaeger S, Secnik, K, Spencer T, Ustün TB, Zaslavsky AM: Patterns and predictors of attention-deficit/hyperactivity disorder persistence into adulthood: results from the national comorbidity survey replication. Biol Psychiatry 2005;57:1442-1451.

2 Biederman J, Mick E, Faraone SV: Age-dependent decline of symptoms of attention deficit/hyperactivity disorder: impact of remission definition and symptom type. Am J Psychiatry 2000;157:816-818.

>3 Fayyad J, De Graaf R, Kessler R, Alonso J, Angermeyer M, Demyttenaere K, De Girolamo G, Haro JM, Karam EG, Lara C, Lépine JP, Ormel J, Posada-Villa J, Zaslavsky AM, Jin R: Crossnational prevalence and correlates of adult atten tion-deficit hyperactivity disorder. Br J Psychiatry 2007;190:402-409.

$\checkmark 4$ Kessler RC, Adler L, Barkley R, Biederman J, Conners CK, Demler O, Faraone SV, Greenhill LL, Howes MJ, Secnik K, Spencer T, Ustin TB, Walters EE, Zaslavsky AM: The prevalence and correlates of adult ADHD in the United States: results from the National Comorbidity Survey Replication. Am J Psychiatry 2006;163:716-723.

$\checkmark 5$ Rösler M, Retz W, Thome J, Schneider M, Stieglitz RD, Falkai P: Psychopathological rating scales for diagnostic use in adults with attention-deficit/hyperactivity disorder (ADHD). Eur Arch Psychiatry Clin Neurosci 2006;256(suppl 1):3-11.
6 American Psychiatric Association: Diagnostic and Statistical Manual of Mental Disorders (DSM-IV), 4th rev. ed. Washington, D.C., American Psychiatric Association, 1994

7 Sobanski E, Brüggemann D, Alm B, Kern S, Deschner M, Schubert T, Philipsen A, Rietschel M: Psychiatric comorbidity and functional impairment in a clinically referred sample of adults with attention-deficit/hyperactivity disorder (ADHD). Eur Arch Psychiatry Clin Neurosci 2007;257:371-377.

8 Cumyn L, French L, Hechtman L: Comorbidity in adults with attention-deficit/hyperactivity disorder. Can J Psychiatry 2009;54:673-683.

$\checkmark$ Holtkamp K, Konrad K, Müller B, Heussen N, Herpertz S, Herpertz-Dahlmann B, Hebebrand $\mathrm{J}$ : Overweight and obesity in children with attention-deficit/hyperactivity disorder. Int $\mathrm{J}$ Obes 2004;28:685-689.

10 Agranat-Meged AN, Deitcher C, Goldzweig G, Leibenson L, Stein M, Galili-Weisstub E: Childhood obesity and attention deficit/hyperactivity disorder: a newly described comorbidity in obese hospitalized children. Int J Eat Disord 2005;37:357359.

11 Curtin C, Bandini LG, Perrin EC, Tybor DJ, Must A: Prevalence of overweight in children and adolescents with attention deficit hyperactivity disorder and autism spectrum disorders: a chart review. BMC Pediatr 2005;5:48.
12 Lam LT, Yang L: Overweight/obesity and attention deficit and hyperactivity disorder tendency among adolescents in China. Int J Obes 2007; 31:584-590.

13 Gruß B, Mueller A, de Zwaan M: Attention-deficit/hyperactivity disorder and obesity. Adipositas 2010;4:143-148.

14 Cortese S, Angriman M, Maffeis C, Isnard P, Konofal E, Lecendreux M, Pupper-Ouakil D, Vincenzi B, Bernardina BD, Mouren MC: Attentiondeficit/hyperactivity disorder (ADHD) and obesity: a systematic review of the literature. Crit Rev Food Sci Nutr 2008;48:524-537.

15 Cortese S, Angriman M: Attention-deficit/hyperactivity disorder and obesity: moving to the next research generation. Pediatrics 2008;122:1155.

16 Waring ME, Lapane KL: Overweight in children and adolescents in relation to attention-deficit/hyperactivity disorder: results from a national sample. Pediatrics 2008;122:1-6.

17 Fleming JP, Levy LD, Levitan RD: Symptoms of attention deficit hyperactivity disorder in severely obese women. Eat Weight Disord 2005;10:10-13.

18 Levy LD, Fleming JP, Klar D: Treatment of refractory obesity in severely obese adults following management of newly diagnosed attention deficit hyperactivity disorder. Int J Obes 2009;33:326-334.

19 Altfas JR: Prevalence of attention deficit/hyperactivity disorder among adults in obesity treatment. BMC Psychiatry 2002;2:9. 
20 Pagoto SL, Curtin C, Lemon SC, Bandini LG, Schneider KL, Bodenlos JS, Ma Y: Association between adult attention deficit/hyperactivity disorder and obesity in the US population. Obesity 2009;17:539-544.

-21 Palazzo Nazar B, Moreira de Sousa Pinna C, Coutinho G, Segenreich D, Duchesne M, Appolinario JC, Mattos P: Review of the literature of attention-deficit/hyperactivity disorder with comorbid eating disorders. Rev Bras Psiquiatr 2008; 30:384-389.

22 Mikami AY, Hinshaw SP, Patterson KA, Lee JC: Eating pathology among adolescent girls with attention deficit/hyperactivity disorder. J Abnorm Psychol 2008; 117:225-235.

$\checkmark 23$ Cortese S, Bernardina BD, Mouren MC: Attention-deficit/hyperactivity disorder (ADHD) and binge eating. Nutr Rev 2007;65:404-411.

24 Davis C: Attention-deficit/hyperactivity disorder: Associations with overeating and obesity. Curr Psychiatry Rep 2010;12:389-395.

25 Retz-Junginger P, Retz W, Blocher D, Weijers HG, Trott GE, Wender PH, Rösler M: Wender Utah Rating Scale. The short-version for the assessment of attention-deficit hyperactivity disorder in adults. Nervenarzt 2002;73:830-838.

26 Retz-Junginger R, Retz W, Blocher D, Stieglitz RD, Georg T, Supprian T, Wender PH, Rösler M: Reliability and validity of the German short version of the Wender-Utah Rating Scale for the retrospective assessment of attention deficit/hyperactivity disorder. Nervenarzt 2003;74:987-993.

27 Rösler M, Retz-Junginger P, Retz W, Stieglitz R: Homburger ADHS-Skalen für Erwachsene (HASE): Untersuchungsverfahren zur syndromalen und kategorialen Diagnostik der Aufmerksamkeitsdefizit-/Hyperaktivitätsstörung (ADHS) im Erwachsenenalter. Göttingen, Hogrefe, 2008

28 Rösler M, Retz W, Retz-Junginger P, Thome J, Supprian T, Nissen T, Stieglitz RD, Blocher D, Hengesch G, Trott GE: Tools for the diagnosis of attention-deficit/hyperactivity disorder in adults. Self-rating behaviour questionnaire and diagnostic checklist. Nervenarzt 2004;75:888-895.

29 Fairburn CG, Beglin SJ: The assessment of eating disorders: interview or self-report questionnaire? Int J Eat Disord 1994;16:363-370.

30 Hilbert A, Tuschen-Caffier B, Karwautz A, Niederhofer H, Munsch S: Eating Disorder Examination - Questionnaire: Evaluation der deutschsprachigen Übersetzung. Diagnostica 2007;53:144-154.

31 Fairburn CG, Cooper PJ: The Eating Disorder Examination (12th edition); in Fairburn CG, Wilson GT (eds): Binge Eating. Nature, Assessment, and Treatment. New York, Guilford Press, 1993, pp 317-360.
32 Hilbert A, Tuschen-Caffier B, Ohms M: Eating Disorder Examination: deutschsprachige Version des strukturierten Essstörungsinterviews. Diagnostica 2004;50:98-106.

33 Mond JM, Hay PJ, Rodgers B, Owen C, Beumont PJV: Validity of the Eating Disorder Examination Questionnaire (EDE-Q) in screening for eating disorders in community samples. Behav Res Ther 2004:42:551-567.

34 Mond JM, Hay PJ, Rodgers B, Owen C: Self-report versus interview assessment of purging in a community sample of women. Eur Eat Disord Rev 2007;15:403-409.

35 Kroenke K, Spitzer RL, Williams JB, Löwe B: An ultra-brief screening scale for anxiety and depression: the PHQ-4. Psychosomatics 2009;50:613-621.

36 Löwe B, Wahl I, Rose M, Spitzer C, Glaesmer H, Wingenfeld K, Schneider A, Brähler E: A 4-item measure of depression and anxiety: validation and standardization of the Patient Health Questionnaire-4 (PHQ-4) in the general population. J Affect Disord 2010;122:86-95.

37 Kroenke K, Spitzer RL, Williams JB: The Patient Health Questionnaire - 2: validity of a two-item depression screener. Med Care 2003;41:1284-1292.

38 Löwe B, Kroenke K, Gräfe K: Detecting and monitoring depression with a two-item questionnaire (PHQ-2). J Psychosom Res 2005;58:163-171.

39 Kroenke K, Spitzer RL, Williams JB., Monahan PO, Löwe B: Anxiety disorders in primary care: prevalence, impairment, comorbidity, and detection. Ann Intern Med 2007;146:317-325.

40 Baron RM, Kenny DA: The moderator-mediator variable distinction in social psychology research: conceptual, strategic, and statistical considerations. J Pers Soc Psychol 1986;51:1173-1182.

41 de Zwaan M, Gruß B, Mueller A, Graap H, Martin A, Glaesmer H, Hilbert A, Philipsen A: The estimated prevalence and correlates of adult ADHD in a German community sample. Eur Arch Psychiatry Clin Neurosci 2011; DOI: 10.1007/s00406-0110211-9.

42 Strimas R, Davis C, Patte K, Curtis C, Reid C, McCool C: Symptoms of attention-deficit/hyperactivity disorder, overeating, and body mass index in men. Eat Behav 2008;9:516-518.

43 Davis C, Levitan RD, Smith M, Tweed S, Curtis C: Association among overeating, overweight, and attention deficit/hyperactivity disorder: A structural equation modelling approach. Eat Behav 2006;7:266-274.

44 Mueller A, Pauli E., de Zwaan M: Is it all about willpower? Executive functioning in obesity. Adipositas 2010;4:131-137.
45 Davis C, Patte K, Levitan RD, Carter J, Kaplan AS, Zai C, Reid C, Curtis C, Kennedy JL: A psycho-genetic study of associations between symptoms of binge eating disorder and those of attention deficit (hyperactivity) disorder. J Psychiatr Res 2009;43:687-696.

46 Wang GJ, Volkow ND, Logan J, Pappas NR, Wong CT, Zhu W, Netusil N, Fowler JS: Brain dopamine and obesity. Lancet 2001;357:354-357.

47 Bazar KA, Yun AJ, Lee PY, Daniel SM, Doux JD: Obesity and ADHD may represent different manifestations of a common environmental oversampling syndrome: a model for revealing mechanistic overlap among cognitive, metabolic, and inflammatory disorders. Med Hypotheses 2006;66:263-269.

48 Philipsen A, Hornyak M, Riemann D: Sleep and sleep disorders in adults with attention deficit/hyperactivity disorder. Sleep Med Rev 2006;10:399405.

49 Philipsen A, Limberger MF, Lieb K, Feige B, Kleindienst N, Ebner-Priemer U, Barth J, Schmahl C, Bohus M: Attention-deficit/hyperactivity disorder as a potentially aggravating factor in borderline personality disorder. Br J Psychiatry 2008;192:118123.

50 Simon V, Czobor P, Bálint S, Mészáros A, Bitter I: Prevalence and correlates of adult attention-deficit hyperactivity disorder: meta-analysis. Br J Psychiatry 2009;194:204-211.

51 Mannuzza S, Klein RG, Klein DF, Bessler A, Shrout P: Accuracy of adult recall of childhood attention deficit hyperactivity disorder. Am J Psychiatry 2002;159:1882-1888.

52 Murphy P, Schachar R: Use of self-ratings in the assessment of symptoms of attention deficit hyperactivity disorder in adults. Am J Psychiatry 2000;157:1156-1159.

53 McGuire MT, Wing RR, Klem ML, Lang W, Hill JO: What predicts weight regain in a group of successful weight losers? J Consult Clin Psychol 1999;67:177-185.

54 McGuire MT, Wing RR, Hill JO: The prevalence of weight loss maintenance among American adults. Int J Obes 1999;23:1314-1319.

55 Glaesmer H, Brahler E: Prevalence estimation of overweight and obesity based on subjective data of body-mass-index (BMI). Gesundheitswesen 2002;64:133-138.

56 Gorber SC, Tremblay M, Moher D, Gorber B: A comparison of direct vs. self-report measures for assessing height, weight and body mass index: a systematic review. Obes Rev 2007;8:307-326.

57 International Association for the Study of Obesity (IASO): Adult Overweight and Obesity in the European Union (EU27). www.easoobesity.org. 